\title{
Fome, desnutrição e cidadania: inclusão social e direitos humanos
}

\section{Hunger, malnutrition and citizenship: social inclusion and human rights}

\section{Flávio Luiz Schieck Valente}

Médico, Mestre em Saúde Pública pela Harvard School of Public Health, Bosto/USA. Relator Nacional para os Direitos Humanos à

Alimentação, Água e Terra Rural - Plataforma Brasileira. DHESC/ ABRANDH. Coordeenador de projetos - Ação Brasileira pela Nutrição e Direitos Humanos -ABRANDH. Membro do Comitê Diretivo do Comitê Permanente de Nutrição da ONU (200I - 2004). Secretário Executivo Internacional da Aliança dos Povos para Ação e Nutrição - APAN (2003 - 2004). Membro da Coordenação Nacional do Fórum Brasileiro de Segurança Alimentar e Nutricional (desde 1998)

E-mail: flaviovalenteœuol.com.br

\section{Resumo}

O artigo faz uma análise crítica do debate atual no Brasil sobre os conceitos de fome e desnutrição e das suas implicações para o processo de elaboração de políticas públicas no país. Fome e desnutrição são eventos relacionados, mas de natureza distinta. Os riscos da redução da fome às suas dimensões estritamente biológicas ou econômicas, para fins de mensuração, são discutidos em relação ao possível impacto sobre a promoção e realização do Direito Humano à Alimentação. Propõe-se o fortalecimento da ótica dos Direitos Humanos na discussão sobre o tema no Brasil. Esta abordagem colabora para uma conceituação mais abrangente e integrada de fome e desnutrição. Ao mesmo tempo, define titularidades, papéis e obrigações do Estado e de diferentes atores sociais que permitem a elaboração de políticas públicas cujas metas e desempenho possam ser monitorados mais facilmente pela sociedade civil. É feita uma breve análise da política de combate à fome do novo governo federal e sugestões são apresentadas para debate.

Palavras-chave: fome, desnutrição, direito humano à alimentação, políticas públicas de alimentação e nutrição. 
Abstract

The paper develops analysis of the ongoing debate in Brazil on the concepts of hunger and malnutrition and of its implications for the elaboration of Public Policies in the country. Hunger and malnutrition are related events, but of distinct nature. The risks of reducing hunger to its strictly biological or economic dimensions, for measurement purposes, are discussed in relation to the possible impact on the promotion and realization of the Human Right to Food. The strengthening of the Human Rights based approach to the theme in Brazil is proposed as it allows for a more encompassing and integrated concept of hunger and malnutrition. The paper also discusses the entitlements and roles of different social actors and right related state obligations, which allow for the elaboration of public policies with goals and performance that can be easily monitored by civil society. A brief analysis of the new Brazilian government policy to combat hunger is presented and suggestions are forwarded for the debate.

Key words: hunger, malnutrition, human right to food, food and nutrition public policies.
A adoção do combate à fome como prioridade central do novo governo federal brasileiro recolocou o tema em debate na esfera política, acadêmica, técnica e operacional. Após alguns meses de intensas discussões, pode parecer para um observador mais desinformado que ninguém sabe exatamente do que está falando, ou que as informações divulgadas se referem a diferentes países. A imprensa tem divulgado declarações que variam desde que não haveria mais fome no país até as que afirmam que existem mais de 50 milhões de famintos no Brasil. O novo governo adota o número de 40 milhões de pessoas que não teriam condições de se alimentar adequadamente todos os dias

Que informação mais se aproxima da realidade? Como definir políticas públicas adequadas a partir de diagnósticos tão diferentes? Infelizmente, não existe uma resposta simples para estas perguntas. Não existe uma verdade única, mas sim diferentes visões de uma mesma realidade.

Fazendo uma metáfora, acho que estamos vivendo o mesmo dilema dos sábios indianos a quem o rei solicitou que examinassem um elefante de olhos vendados e lhe informassem do que se tratava. 0 que palpou a pata, definiu que se tratava do tronco de uma árvore; aquele que examinou a orelha, identificou um leque, e assim por diante.

Urban Jonsson, em um artigo originalmente publicado há mais de 20 anos (Valente, 1986), já levantava que cada área profissional tende a olhar para a "fome" de um jeito diferente, e propor ações que decorrem desta visão. 0 profissional da saúde "enxerga" desnutrição e doença e propõe vacinação, saneamento, aleitamento materno, etc. $\mathrm{O}$ agrônomo "diagnostica" falta de alimentos e propõe maior produção de alimentos, ajuda alimentar, etc. $\mathrm{O}$ educador vê "ignorância e hábitos alimentares inadequados" e propõe educação alimentar. Os economistas clássicos "identificam" má distribuição de alimentos e propõem uma melhor política fiscal, geração de emprego e renda, etc. Os planejadores diagnosticam "falta de coordenação" e propõem a criação de conselhos de alimentação e nutrição e capacitação.

Infelizmente, o debate atual reflete exatamente o mesmo problema. As pessoas não estão falando sobre diferentes realidades, mas sim estão olhando para o mesmo Brasil com diferentes olhares, o que acaba certamente levando a diagnósticos muito diferentes. 0 
mais grave é que a adoção de somente um dos olhares, seja qual for o escolhido, dificilmente levará à elaboração de políticas, programas e ações que efetivamente reduzam o sofrimento das pessoas que hoje vivem a realidade diuturna da fome, da insegurança alimentar, da desnutrição, e da desumanização nelas embutida.

A questão da alimentação, da fome e da má nutrição não pode ser olhada exclusivamente em sua dimensão econômica (acesso à renda), alimentar (disponibilidade de alimentos) ou biológica (estado nutricional). 0 ato de se alimentar e alimentar familiares e amigos é uma das atividades humanas que mais reflete a enorme riqueza do processo histórico de construção das relações sociais que se constituem no que podemos chamar de "humanidade", com toda a sua diversidade, e que está intrinsecamente ligado à identidade cultural de cada povo ou grupo social. (Valente, 2002).

A alimentação humana se dá na interface dinâmica entre o alimento (natureza) e o corpo (natureza humana), mas somente se realiza integralmente quando os alimentos são transformados em gente, em cidadãos e cidadãs saudáveis.

Por estas características, uma abordagem adequada ao tema exige a incorporação do quadro de referencia dos Direitos Humanos, que permite um olhar holístico embasado nos princípios básicos de universalidade, equidade, indivisibilidade, inter-relação na realização, respeito à diversidade e não discriminação.

Como bem define o Comentário Geral 12, do Comitê de Direitos Econômicos, Sociais e Culturais da ONU, a realização do direito humano à alimentação adequada não pode ser reduzida ao mero fornecimento de uma ração básica nutricionalmente balanceada (CDESC, 1999) nem tampouco à constatação da eutrofia nutricional.

Um escravo bem nutrido não tem seu direito humano à alimentação garantido, porque ele ou ela continua escravo, e portanto, violado/a em sua humanidade. Um adulto ou uma criança que se alimenta do lixo, mesmo que "bem nutrida", continua a ter seu direito humano violentado, pois ela ainda tem fome e, mais do que tudo, tem sua cidadania violentada. Por outro lado, uma pessoa que tenha acesso a alimentos em quantidade e qualidade suficiente, mas que está enferma ou não tem condições para preparar este alimento, também tem seu direito humano à alimentação violado, porque não consegue realizar a transformação do alimento em vida, em saúde, em humanidade.

Dentro desta perspectiva, tanto a fome como a má nutrição e a desnutrição constituem-se em manifestações claras de violações do Direito Humano à Alimentação Adequada.

A incorporação da abordagem de Direitos Humanos na elaboração de Políticas Públicas de promoção da Segurança Alimentar e Nutricional encontra forte respaldo em tratados internacionais e na legislação nacional, aportando uma nova forma de analisar o tema da fome e da desnutrição, que é sumarizada a seguir com base no texto do relatório nacional apresentado à Comissão de Direitos Humanos da ONU, em abril de 2003, pela Relatoria Nacional para os Direitos Humanos à Alimentação, Água e Terra Rural. (Valente et al, 2003)

\section{Direito Humano à Alimentação e Nu- trição Adequadas}

O direito humano à alimentação adequada está previsto na Declaração Universal dos Direitos Humanos:

Artigo XXV - 1. Toda pessoa tem direito a um padrão de vida capaz de assegurar a si e a sua família saúde e bem-estar, inclusive alimentação, vestuário, habitação, cuidados médicos e os serviços sociais indispensáveis, o direito à segurança, em caso de desemprego, doença, invalidez, viuvez, velhice ou outros casos de perda dos meios de subsistência em circunstâncias fora de seu controle." (ONU, 1948)

0 artigo 11 do Pacto Internacional dos Direitos Econômicos, Sociais e Culturais traz o detalhamento do referido Direito e propõe mecanismos de operacionalização do mesmo:

"Los Estados Partes en el presente Pacto reconocen el derecho de toda persona a un nivel de vida adecuado para sí y su familia, incluso alimentación, vestido y vivienda adecuados, y a una mejora continua de las condiciones de existencia.

1) Los Estados Partes tomarán medidas apropiadas para asegurar la efectividad de este derecho, reconociendo a este efecto la importancia esencial de la cooperación internacional fundada en el libre consentimiento.

2) Los Estados Partes en el presente Pacto, reconocien- 
do el derecho fundamental de toda persona a estar protegida contra el hambre, adoptarán, individualmente y mediante la cooperación internacional, las medidas, incluidos los programas concretos, que se necesitan para: a) Mejorar los métodos de producción, conservación y distribución de alimentos mediante la plena utilización de los conocimientos técnicos y científicos, la divulgación de principios sobre nutrición y el perfeccionamiento o la reforma de los regímenes agrarios de modo que se logren la explotación y la utilización más eficaces de las riquezas naturales;" (CDESC,1966)

Finalmente, a clarificação do conteúdo deste direito humano está contida no Comentário Geral no 12 , do Comitê de Direitos Econômicos, Sociais e Culturais:

“... o direito à alimentação adequada é indivisivelmente ligado à dignidade inerente à pessoa humana e é indispensável para a realização de outros direitos humanos consagrados na Carta de Direitos Humanos. Ele é também inseparável da justiça social, requerendo a adoção de políticas econômicas, ambientais e sociais, tanto no âmbito nacional como internacional, orientadas para a erradicação da pobreza e a realização de todos os direitos humanos para todos..." (grifos do autor) (CDESC, 1999)

O Comentário Geral também define que:

"O direito à alimentação adequada realiza-se quando cada homem, mulher e criança, sozinho ou em companhia de outros, tem acesso físico e econômico, ininterruptamente, à alimentação adequada ou aos meios para sua obtenção. 0 direito à alimentação adequada não deverá, portanto, ser interpretado em um sentido estrito ou restritivo, que o equaciona em termos de um pacote mínimo de calorias, proteínas e outros nutrientes específicos. 0 direito à alimentação adequada terá de ser resolvido de maneira progressiva. No entanto, os estados têm a obrigação precípua de implementar as ações necessárias para mitigar e aliviar a fome, como estipulado no parágrafo 2 do artigo 11, mesmo em épocas de desastres, naturais ou não" (CDESC,1999)

A adequação da alimentação, segundo o mesmo comentário, incorpora aspectos relacionados à: a) diversidade e adequação nutricional e cultural da dieta, incluindo a promoção do aleitamento materno; b) necessidade de estar livre de substâncias nocivas; c) proteção contra a contaminação; c) existência de in- formação sobre a adequação de dietas e conteúdo nutricional dos alimentos.

Há, no presente momento, um grupo de trabalho intergovernamental, secretariado pela FAO, instituído para elaborar Diretrizes Voluntárias para a implementação nacional do Direito Humano à Alimentação, até 2005, com base em decisão da Cúpula Mundial da Alimentação, cinco anos depois, realizada em Roma, 2002.

Neste debate será fundamental a delimitação de quais são as dimensões claras das titularidades do portador do direito humano à alimentação adequada, ou seja, o que estes portadores podem reclamar como direito, e as correspondentes obrigações dos estados, sociedades e outros atores relevantes, incluindo companhias multinacionais e organismos intergovernamentais, no âmbito da proteção, do respeito, da promoção e da realização do direito. A contribuição do Brasil será fundamental neste debate.

O conceito de Direito Humano à Alimentação vem sendo discutido com profundidade no Brasil, especialmente desde a criação da Ação da Cidadania Contra a Fome, a Miséria e Pela Vida, em 1992, que desencadeou um amplo debate sobre o combate à exclusão social no contexto da promoção da cidadania e dos direitos humanos.

Hoje se desenvolve o conceito que o direito humano à alimentação deve ser visto como inseparável do direito humano à nutrição, na medida em que o alimento só adquire uma verdadeira dimensão humana quando transformado em um ser humano bem nutrido, saudável, digno e cidadão. (Valente, 2002).

Assim, a realização do direito humano à alimentação adequada depende de muito mais do que da simples disponibilidade de alimentos, mesmo que saudáveis. Depende do respeito a práticas e hábitos alimentares, do estado de saúde das pessoas, da prestação de cuidados especiais a grupos humanos social e biologicamente vulneráveis (crianças, gestantes, idosos, portadores de necessidades especiais, entre outros) e de estar inserido em um processo de construção da capacidade de todo ser humano de alimentar e nutrir a si próprio e à sua família, com dignidade, a partir do seu trabalho no campo ou na cidade. Esta conceituação mostra a indivisibilidade e interrelação entre o direito humano à alimentação adequada e à nutrição e o direito humano à saúde. 
Um exemplo claro que a realização do direito humano à alimentação só ocorre com a realização simultânea do direito humano à nutrição está na relação mãe-feto durante o período gestacional e de aleitamento exclusivo.

O direito humano à alimentação do feto, no período intrauterino, depende diretamente da realização do direito humano à alimentação e nutrição da mãe. 0 estado nutricional da mãe no momento da concepção terá impacto sobre a realização do direito humano à alimentação adequada da criança, mesmo que a mãe se alimente adequadamente durante a gestação. Caso a mãe não tenha seu direito à nutrição garantindo, o feto não terá nem o seu direito à alimentação nem à nutrição realizados, com um profundo impacto negativo sobre o seu desenvolvimento intrauterino e neonatal. 0 mesmo ocorre no período do aleitamento exclusivo.

A realização do direito humano à nutrição da mãe, portanto, é parte integrante e pré-requisito para a realização do direito à alimentação e nutrição da criança. Mesmo reconhecendo que isto implica em que a titularidade do direito à alimentação adequada da criança implique em mais do que o simples provimento de alimentação adequada à mãe. Implica em que a mãe, bem como a criança, tenham seu direito humano à nutrição adequada realizado, incluídos aí os aspectos relativos ao direito ao cuidado, a condições de vida que promovam a saúde e à atenção à saúde.

A realização do direito humano à alimentação adequada implica em obrigações específicas do Estado e da sociedade de respeitar, proteger, promover e prover: a) acesso físico e econômico a uma alimentação saudável e diversificada de forma sustentável; b) condições que propiciem um cuidado adequado na escolha, preparação e ministração da alimentação (higiene, preparação de alimentos, creche, etc.); c) condições de vida que promovam a saúde e d) atenção integral à saúde.

Neste contexto, portanto, violações contra o direito humano à alimentação adequada podem decorrer de inadequações na realização de qualquer uma destas dimensões, sendo legítima a impetração de recursos administrativos e legais no sentido da reparação das mesmas. Violações podem ocorrer também quando a ingestão excessiva ou inadequada de alimentos, por falta de acesso à informação ou à uma alimentação de qualidade, leva ao surgimento de problemas nutricionais ou de saúde decorrentes de práticas alimentares inadequadas.

De forma mais detalhada, a realização do direito humano à Alimentação e Nutrição adequadas depende: a) da disponibilidade de alimentos saudáveis e seguros, produzidos de forma sustentável; b) da possibilidade de acesso aos mesmos, seja pela produção para consumo, seja por um trabalho que gere a renda necessária; c) da possibilidade de acesso a alimentos culturalmente adequados; d) da existência de mecanismos de transporte e armazenamento adequados; e) de condições de transformação adequada, com higiene, dos alimentos no domicílio ou em espaços públicos (água limpa, saneamento adequado, utensílios, refrigerador, combustível, etc); f) das condições de vida e de habitação das famílias; g) do nível de informação sobre higiene e práticas e hábitos alimentares saudáveis; h) das condições de saúde das pessoas e famílias; i) do acesso a serviços de promoção e atenção à saúde e j) de serviços de controle de qualidade dos alimentos, entre outros.

Base legal para a garantia do direito também pode ser encontrada em uma série de dispositivos constitucionais e da legislação nacional que acolhem o conceito exposto. Um exemplo claro é o reconhecimento da alimentação e da nutrição como pré-requisitos fundamentais à realização do direito à saúde nos artigos 6 e 23 da Constituição Federal (CF, 1988). A constituição federal também reconhece a obrigação do Estado em garantir o direito humano à alimentação dos escolares em seu artigo 208, que trata do direito à educação e de sua efetivação mediante o ensino fundamental público e gratuito, incluindo a implementação de Programa de Suplementação Alimentar (CF, 1988).

O Estatuto da Criança e do Adolescente, artigo $4^{\circ}$, estabelece o direito humano à alimentação das crianças e adolescentes como prioridade absoluta (ECA, 1990). A Política Nacional de Alimentação e Nutrição, do Ministério da Saúde, reconhece a obrigação do estado brasileiro em garantir a realização do direito humano à alimentação para todos os cidadãos e busca articular todas suas propostas de ação neste sentido. 


\section{Os conceitos e seu impacto no diag- nóstico da situação alimentar e nutri- cional do povo brasileiro}

Há pelo menos duas polêmicas centrais em relação ao diagnóstico alimentar e nutricional no Brasil. Uma, brevemente mencionada anteriormente, está centrada na disputa técnica e política entre diferentes abordagens conceituais do tema. A outra está no âmbito da identificação de indicadores e da metodologia adequada para a aferição da magnitude dos problemas existentes. As duas estão interligadas. Só se pode medir algo que está claramente definido.

No entanto, existem duas dificuldades adicionais. Primeira, o Brasil tem uma base de dados ainda inadequada, especialmente no que tange ao monitoramento dos distúrbios nutricionais e de suas conseqüências sobre a saúde e a mortalidade de grupos específicos. Segunda, as dimensões da fome e da má nutrição no Brasil são muitas e não podem ser analisadas exclusivamente a partir de análises estatísticas tradicionais. As diferentes realidades exigem uma avaliação qualitativa para que se consiga efetivamente chegar ao âmago das questões e orientar a elaboração e implementação de políticas públicas que tenham resolutividade.

Aprofundando um pouco a dimensão conceitual, a língua portuguesa não tem palavras específicas para "famine" (fome aguda epidêmica) e para "starvation" (processo agudo de fome/desnutrição que pode levar à morte). Assim, a palavra fome no português pode ser usada para uma enorme variedade de situações, desde a situação mais simples e fisiológica de estar com vontade de comer até a situação extrema da fome epidêmica, como mencionado anteriormente.

Alguns conceituados profissionais da saúde que trabalham com a área de nutrição adotam um conceito de fome que reduz a mesma a alterações de massa corpórea (redução de peso ou de massa corpórea abaixo dos níveis considerados saudáveis). Ou seja, a fome se manifestaria em quadro de subnutrição, pela ausência de alimentos, em associação ou não com outros fatores (Monteiro, 2003; Victora, 2003). Segundo os mesmos autores, a maior parte dos quadros de desnutrição observados em crianças não são decorrentes da falta de alimentos, mas sim devido a outros fa- tores como falta de atenção de saúde adequada ao prénatal e à infância, falta de saneamento básico, água contaminada, entre outros. Dentro desta visão, a fome já não seria um problema tão grave no Brasil.

Por outro lado, é fundamental reconhecer que estes autores estão corretos ao afirmar que muitas crianças, e mesmo adultos, não estão desnutridos porque lhes falta alimentos, mas também acesso às outras dimensões necessárias à promoção de uma boa nutrição (cuidado, saúde, habitação, renda, etc). Isto implica em que qualquer Programa Nacional de combate à Fome e à desnutrição deva ter uma forte articulação com a promoção de iniciativas de inclusão social (rural e urbana) e com o fortalecimento e universalização das ações da área da Saúde e Nutrição.

A partir de um outro olhar, o novo governo federal, com base em estudo coordenado pelo Instituto da Cidadania, ressaltando que não se pode tratar fome e pobreza como sinônimos, considera que "as pessoas que não têm renda suficiente para adquirir uma cesta básica" são aquelas que "passam fome" ou, pelo menos, são vulneráveis a isso (Instituto da Cidadania, 2001). Com base neste critério, o mesmo estudo chega à estimativa de 44 milhões de pessoas em situação de insegurança alimentar, ou seja, em risco de passar fome, para o ano de 1999. A partir deste enfoque, a ênfase nos primeiros meses de governo tem sido na implementação de iniciativas que garantam o acesso físico e econômico aos alimentos por parte destas pessoas, seja pelo alavancamento de ações solidárias, seja pela implementação de programas de transferência de renda, especificamente para a compra de alimentos (cartão alimentação) ou não (Bolsa Escola, bolsa Alimentação, bolsa renda, entre outros).

Dentro de uma outra abordagem, a qual o autor deste artigo subscreve, a fome não pode ser reduzida nem à sua dimensão econômica nem ao seu impacto biológico mensurável. Como apresentado no início do artigo, a fome e a alimentação, dentro de uma perspectiva de direitos humanos, são facetas de um fenômeno muito mais amplo do que isto. Elas incorporam dimensões relacionadas a diferentes necessidades históricas, culturais, psicológicas e espirituais dos seres humanos, incluindo a questão básica da dignidade.

O conceito de fome, no Brasil, utilizado por diferentes setores da população, abarca desde aquela sensação fisiológica ligada à vontade de comer, conheci- 
da de todos nós, até as formas mais brutais de violentação do ser humano, ligadas à pobreza e à exclusão social. Ver os filhos passarem fome é passar fome. Comer lixo é passar fome. Comer o resto do prato dos outros é passar fome. Passar dias sem comer é passar fome. Comer uma vez por dia é passar fome.Ter que se humilhar para receber uma cesta básica é passar fome. Trocar a dignidade por comida é passar fome. Ter medo de passar fome é estar cativo da fome. Estar desnutrido também é passar fome, mesmo que a causa principal não seja falta de alimento.

O conceito de má nutrição, por outro lado, é de uso quase restrito à área da saúde. Refere-se às manifestações corpóreas - clínica, antropométrica e laboratorialmente constatáveis - decorrentes da interação de uma complexidade de determinantes do estado nutricional, tais como: grau de segurança alimentar domiciliar; cuidados no nível familiar e comunitário; condições de vida e qualidade dos serviços de atenção à saúde (UNACC/SCN, 200o). A má nutrição, enquanto conceito abrangente, engloba tanto a desnutrição decorrente de carências nutricionais (energia, proteína e micronutrientes) como os quadros causados por uma ingestão excessiva ou desbalanceada de nutrientes, tais como a obesidade, dislipidemias e outras doenças crônicas.

É importante ressaltar que a maior parte dos casos de má nutrição, sejam aqueles com características carenciais ou aqueles associados a excessos ou desequilíbrios nutricionais, não pode ser atribuída exclusivamente ao nível inadequado de ingestão de alimentos e/ou nutrientes. Enquanto facetas de um mesmo processo social e biológico, a má nutrição e a fome são reflexos das complexas relações humanas que estabelecem quais seres humanos tem direito ao quê e quando.

A partir das conceituações apresentadas, inferimos que fome e desnutrição são diferentes dimensões de um mesmo evento e que, portanto, demandam formas também distintas de avaliar sua magnitude. A má nutrição, por sua definição e dimensão essencialmente biológica, pode ser aferida por métodos quantitativos: antropometria, exames laboratoriais e sinais e sintomas clínicos, sem que isto elimine a importância da avaliação qualitativa do quadro clínico nutricional no contexto da vida de cada ser humano.

Não se pode dimensionar a fome humana somente a partir de indicadores de disponibilidade de alimentos no mercado ou no domicílio, de gastos famili- ares com alimentos, de inquéritos de consumo alimentar, ou mesmo de indicadores de estado nutricional, diretos ou indiretos. A fome tem facetas fortemente subjetivas.

Qualquer tentativa de reduzir a alimentação e a fome à sua dimensão estritamente nutricional, seja do ponto de vista de ingestão de nutrientes seja de estado nutricional, representa limitar o ser humano à sua biologicidade, limitar o corpo humano a um instrumento ou máquina e a comida a nutrientes, combustível e partes de reposição. Nós somos muito mais complexos do que isto.

Qualquer tentativa de reduzir a alimentação e a fome à sua dimensão estritamente econômica ou de disponibilidade de alimentos, representa submeter integralmente o processo alimentar às leis do mercado onde o alimento comparece como mercadoria e o ser humano como consumidor, quando tem condições para comprar.

Neste sentido, é cientificamente incorreto mensurar o nível de fome exclusivamente a partir de dados de renda, de subnutrição em adultos e desnutrição em crianças.

No entanto, ter parâmetros individuais e populacionais da fome, da má alimentação, da desnutrição é fundamental para orientar a elaboração e implementação de políticas e programas públicos capazes de promover um desenvolvimento humano sustentável, que tenha como um dos eixos centrais a redução das desigualdades sociais e econômicas e a erradicação da fome.

Para isto, esta mensuração tem que partir de uma nova conceituação que incorpore a dimensão da indivisibilidade dos direitos humanos e da visão de mundo das populações excluídas, e tenha como princípio e finalidade última a universalização da humanidade.

\section{Implicações da questão conceitual pa- ra a elaboração de políticas públicas}

Alguns passos são fundamentais para que se avance na elaboração de uma Política Nacional de Segurança Alimentar e Nutricional que consiga promover a realização do Direito Humano à Alimentação. 0 primeiro passo consiste no estabelecimento de um processo de debate técnico e político que permita a construção de um consenso técnico e político sobre o que 
se define como fome, como insegurança alimentar, como desnutrição, como subnutrição, etc. O segundo, a partir dos conceitos definidos, deve concentrar-se na identificação de indicadores que possam monitorar a evolução da situação alimentar e nutricional. 0 terceiro momento deverá ser dedicado ao estabelecimento de metas a serem alcançadas em relação a cada um dos indicadores e dos prazos necessários para fazêlo. Por último, devemos identificar quais ações e programas, desenvolvidos pelos distintos setores governamentais e da sociedade, são prioritários para atingir as metas, e a partir disto definir os recursos humanos e financeiros necessários para o seu sucesso, incluindo-se aí a implementação e fortalecimento dos mecanismos de monitoramento da evolução dos indicadores selecionados.

É importante ressaltar que se temos problemas com a mensuração da fome, também os temos em relação à da má-nutrição.

Estudos nacionais realizados ao longo das duas ultimas décadas demonstram uma redução progressiva da prevalência da desnutrição infantil. No entanto, não temos informações recentes. Dados de 1996 apontam para uma prevalência de 10,5\% de nanismo nutricional na população menor de 5 anos e de 5,6\% de baixo peso para idade. Isto significa que cerca de um milhão e meio de crianças ainda apresentam desnutrição no país. A situação do Nordeste brasileiro apresenta uma situação muito mais grave, com índices duas vezes mais altos que a média nacional (Monteiro, 2000).

Em relação aos problemas nutricionais decorrentes de carências de micronutrientes, os dados são mais precários, só existindo estudos pontuais. No entanto, há fortes indicativos que o quadro de anemia ferropriva vem se agravando nos últimos anos, inclusive nos setores médios da população brasileira, e que ainda se mantém um quadro preocupante de hipovitaminose A em algumas regiões do país (OPAS, 2002).

São, também, totalmente insuficientes e desatualizadas as informações sobre a prevalência de sobrepeso, obesidade e das doenças crônicas associadas em crianças e adultos. Isto é preocupante, especialmente em se tendo em conta o conhecimento científico acumulado, divulgado em sucessivos relatórios da ONU, que aponta para o risco significativamente aumentado de surgimento de doenças crônicas não transmis- síveis em crianças e adultos vítimas de desnutrição na infância (ONU, 200o).

A precariedade dos dados sobre o tema, apesar da abundante base de dados existente no Brasil, nos remete a termos que discutir prioridades. Será impossível, em curto e médio prazo, produzir todas as informações necessárias para termos um quadro realista da situação alimentar e nutricional da população brasileira, mesmo que cheguemos a um consenso sobre a questão conceitual.

Isto sem falar que não existem dados nutricionais no Brasil que permitam sua desagregação por raça ou por etnia, na medida em que esta preocupação somente surge recentemente com o crescimento da protagonismo dos afrodescendentes e dos povos indígenas.

Enquanto avançamos na construção deste novo quadro de referência e o colocamos em prática, é fundamental que busquemos o estabelecimento de alguns acordos mínimos que possam orientar nossa atuação enquanto técnicos e seres políticos.

\section{Conclusões}

A priorização do combate à fome pelo novo governo federal enquanto eixo norteador das políticas econômicas e sociais e do próprio novo modelo de desenvolvimento, e não só como objeto de políticas de caráter exclusivamente compensatório, é pioneira e deve receber todo o nosso apoio.

O estabelecimento de políticas públicas conseqüentes que possam levar à superação da fome e da desnutrição exige um esforço de integração e articulação de ações governamentais, e destas com as iniciativas da sociedade civil, partindo da re-pactuação política e técnica dos conceitos básicos de fome, desnutrição, pobreza e mesmo alimentação e nutrição como direitos humanos, e não só da redefinição das linhas de pobreza. Nenhum conceito é neutro. Todo conceito traz nele embutidas visões de mundo e, portanto, delimita as possibilidades de superação ou não dos problemas identificados.

No momento, estamos restritos a conceitos que ainda não incorporam a riqueza dos processos históricos, políticos, sociais e científicos vividos pelo Brasil, nos tempos recentes, especialmente no que se refere ao crescente protagonismo político e cultural das classes populares, nas diferentes esferas da vida brasileira. 
Os conceitos a serem utilizados neste novo momento têm que incorporar o olhar e a visão de mundo daqueles que vivem a realidade de fome e exclusão, enriquecendo a discussão e rompendo com as barreiras corporativas impostas pela academia e pela tecnocracia. Somente a partir desta nova compreensão da realidade poderemos mensurar de forma mais aproximada as condições de fome e desnutrição do nosso povo, desenvolver políticas adequadas e monitorar seu impacto.

Ao mesmo tempo, os técnicos responsáveis pela elaboração das políticas terão que sair de seus casulos profissionais, conformados por uma formação acadêmica fragmentadora e reforçados pelas estruturas estanques dos órgãos públicos setoriais, que dificultam a transdisciplinaridade necessária ao enfrentamento da fome e da desnutrição.

Cabem duas tarefas centrais neste momento a todos os setores da sociedade brasileira. Por um lado, a de cobrar que o novo governo federal cumpra os compromissos assumidos de: 1) superar políticas fragmentárias e assistencialistas no tratamento da fome e da desnutrição; 2) promover uma verdadeira articulação de políticas e programas emergenciais e estruturais, de promoção do Direito Humano à Alimentação, por meio da implementação de uma Política Nacional de Segurança Alimentar e Nutricional, integradora e transversal.

Por outro, a de dar sua contribuição para a construção de um novo modelo de desenvolvimento para o país. Nenhum governo, sem o apoio efetivo da maioria da sociedade brasileira, será capaz de atingir esta meta. São imensos os desafios nacionais e internacionais que terão que ser ultrapassados para que consigamos efetivamente reduzir as brutais desigualdades que maculam a humanidade e cidadania de todos nós.

O Brasil precisa mais do que um projeto de combate à fome. Precisamos de uma política nacional de promoção de alimentação, nutrição e modos de vida saudáveis, enquanto parte integrante de um processo de desenvolvimento humano sustentável, com a meta central de promover a dignidade humana e a redução da discriminação e das desigualdades.

\section{Referências Bibliográficas}

CDESC. "Comentário Geral $\mathrm{n}^{0} 12$ - o direito humano à alimentação" in: VALENTE, F.L.S. Direito Humano à Alimentação - desafios e conquistas. $1^{\mathrm{a}}$ ed. São Paulo, Cortez Editora, 2002. p 261-272

ESTATUTO da Criança e do Adolescente (ECA) Lei $\mathrm{n}^{\circ}$ 8069, de 13 de julho de 199o. <http://www.mj. gov.br/sedh/dca/eca.htm>. Acessado no dia 14 de março de 2003

IPEA, SEDH, MRE. A segurança Alimentar e Nutricional e o Direito Humano à Alimentação no Brasil. Brasília, IPEA, 2002. p 23.

INSTITUTO DA CIDADANIA. Projeto Fome Zero: uma proposta de política de Segurança Alimentar para o Brasil. São Paulo, Instituto da Cidadania, 2001. $118 \mathrm{p}$.

JONSSON, U. "As causas da fome" in: VALENTE, F.L.S. (org) Fome e desnutrição: determinantes sociais. São Paulo, Cortez Editora, 1986 : 48-65

MONTEIRO, C.A. Velhos e novos males da saúde no Brasil a evolução do país e de suas doenças. São Paulo, HUCITEC/NUPENS/USP, $2^{\text {a }}$ edição revisada e aumentada/20oo.

MONTEIRO, C.A. Fome, pobreza e desnutrição:além da semântica. São Paulo, 2003. mimeo.

MS/CGPAN - Ministério da Saúde - Coordenação Geral da Política de Alimentação e Nutrição. Política Nacional de Alimentação e Nutrição <http://portal. saude.gov.br/alimentacao/politica.cfm $>$. Acessado no dia 14 de março de 2003.

OPAS. Bibliografia sobre deficiência de micronutrientes no Brasil 199o-20oo. Brasília, OPAS, 2002

ONU. Declaração Universal dos Direitos Humanos. Nova Iorque, ONU, 1948 <http://www.unhchr.ch/ udhr/lang/por.htm $>$. Acessado no dia 23 de junho de 2003 .

ONU. Pacto Internacional dos Direitos Econômicos, Sociais e Culturais. Nova Iorque, ONU, 1966. <http://www.unhchr.ch/spanish/html/menu3/b/ a_cescr_sp.htm>. Acessado no dia 23 de junho de 2003. 
ONU -United Nations Administrative Committee on Coordination - Sub Commmittee on Nutrition (ACC/SCN) Ending Malnutrition by 2020: an agenda for the Change in the Millenium. Geneva, ACC/ SCN, 200o. (coordinated by Philip James)

UNITED NATIONS Administrative Committee on Coordination - Sub Committee on Nutrition (UNACC/ ACC/SCN) (in collaboration with IFPRI) 4th. Report on the World Food Situation - Nutrition throughout the life Cycle. Geneva, ACC/SCN (in collaboration with IFPRI), 2000. $132 \mathrm{pg}$.

VALENTE, F.L.S. Direito Humano à Alimentação desafios e conquistas. $1^{\mathrm{a}}$ ed. São Paulo, Cortez Editora, 2002. $272 \mathrm{pg}$.
VALENTE, F.L.S. "Segurança Alimentar e Nutricional: transformando natureza em gente" in: VALENTE, F. L. S. Direito Humano à Alimentação - desafios e conquistas. $1^{\mathrm{a}}$ ed. São Paulo, Cortez Editora, 2002. p. $103-136$.

VALENTE, F.L.S; Burity, V. "Direitos Humanos à Alimentação, água e terra rural" in: Relatório Brasileiro sobre Direitos Humanos Econômicos, Sociais e Culturais. Plataforma Brasileira de Direitos Humanos Econômicos, Sociais e Culturais. Recife, Edições Bagaço, 2003 p 341-403

VICTORA, C. Entrevista. Folha de São Paulo, o4 de março de 2003 . 